\title{
Experiências curriculares e formação de professores: uma tessitura coletiva no âmbito do Pibid/UFES
}

Curricular experiences and the formation of teachers: a collective organization around the Pibid/UFES

Arnaldo Pinto Junior*

Katia Valeska Azevedo**

Mônica Cardoso de Lima ${ }^{* * *}$

\section{Resumo}

$\mathrm{O}$ artigo apresenta relatos de experiências vivenciadas no âmbito do Pibid/ UFES, a partir dos quais os professores responsáveis refletem acerca dos desdobramentos na formação dos bolsistas de iniciação à docência e das próprias práticas de ensino e pesquisa. Desenvolvido em parceria com instituições públicas da cidade de Vitória (ES), o subprojeto de Licenciatura em História trabalhou com turmas de Ensino Fundamental e Médio para que os licenciados pudessem conhecer e debater distintas condições e demandas. Ao considerarmos as atuais dinâmicas escolares e perspectivas dos currículos acadêmicos, destacamos experiências que potencializam análises relativas aos projetos de ensino interdisciplinares, suas conexões com o perfil bacharelesco dos cursos de Licenciatura

\section{Abstract}

The article presents reports on experiences around the Pibid/UFES, based on what the leading teachers reflect on the unfolding of the formation of teaching grant receivers, as well as the teaching and researching practices. In a joint development with the public institutions of the city of Vitória (ES), the subproject of graduation in History worked with Fundamental and High School classes so that the teacher could learn and debate various conditions and demands. While considering the current school dynamics and the perspectives of academic curricula, we highlight the experiences that empower analysis related to the projects of interdisciplinary teaching, their connection with the bachelor profile of the courses in teaching, and the understanding of what is

\footnotetext{
* Universidade Federal de São Carlos (UFSCar), Programa de Pós-Graduação em Educação da Universidade Federal do Espírito Santo (UFES). Vitória, ES, Brasil. apjbrasil@hotmail.com

** Escola Estadual de Ensino Fundamental e Médio Irmã Maria Horta. Vitória, ES, Brasil. azevedokva@hotmail.com

*** Escola Municipal de Ensino Fundamental José Áureo Monjardim. Vitória, ES, Brasil. mhocardoso@hotmail.com
} 
e a compreensão do que é conhecimento histórico para graduandos e estudantes da Educação Básica.

Palavras-chave: formação de professores; ensino de História; produção de conhecimento. the historical knowledge for Basic Education graduates and students.

Keywords: formation of teachers; teaching of History; knowledge production.

\section{Apresentando um PROCESSO DE TESSITURA COLETIVA}

Abordar um processo formativo sempre é um desafio para qualquer pesquisador que pretenda estudá-lo. Tal desafio é constituído por inúmeros elementos, entre os quais estão análises dos objetivos estabelecidos na proposta de formação, da participação dos sujeitos para sua consecução, dos produtos culturais resultantes e dos impactos sociais derivados do desenvolvimento do referido processo. Nesses e em outros aspectos, as possíveis análises efetivamente são de grande monta.

Gostaríamos de esclarecer aos leitores que este texto apresenta relatos de experiências vivenciadas por três professores que trabalharam juntos no âmbito do Programa Institucional de Bolsa de Iniciação à Docência (Pibid) da Universidade Federal do Espírito Santo (UFES). Ao partirmos de nossas experiências, temos a intenção de ampliar as reflexões acerca dos processos formativos de licenciados do curso de História que fizeram (ou ainda fazem) parte do Pibid. Também pretendemos refletir sobre as formas com que os processos focalizados estão estimulando novas percepções de formação nos próprios professores responsáveis, ou seja, nos coordenadores lotados nas universidades e nos professores supervisores que atuam na Educação Básica.

Antes de encaminharmos as discussões relativas às experiências vivenciadas, explicitamos em linhas gerais as trajetórias do trabalho ainda em curso. $\mathrm{O}$ subprojeto da área de Licenciatura em História do Pibid/UFES é desenvolvido desde agosto de 2012. Na primeira fase, ${ }^{1}$ entre agosto de 2012 e fevereiro de 2014, o subprojeto contava com a participação de 16 bolsistas de iniciação à docência (ID), 2 bolsistas de supervisão e 1 bolsista de coordenação. Na segunda fase, ${ }^{2}$ iniciada em março de 2014 (com previsão de término coincidindo com os primeiros meses letivos de 2018), o subprojeto conta com a participação de 24 bolsistas ID, 4 bolsistas de supervisão e 2 bolsistas de coordenação. 
Para efeito de recorte temporal, optamos por focalizar o período que abrange desde o início da primeira fase até o final do ano letivo de 2014. Justificamos tal recorte pelos seguintes motivos: os autores desenvolveram em conjunto as atividades do subprojeto de Licenciatura em História a maior parte desse tempo; após o final do ano letivo de 2014, o primeiro coordenador do subprojeto (professor Arnaldo Pinto Junior) deixou a UFES e, consequentemente, o programa, para assumir uma vaga na Universidade Federal de São Carlos (UFSCar); e até o momento da produção deste texto (entre os meses de fevereiro e março de 2015), as professoras supervisoras que ainda continuam no programa não reuniam elementos para refletir sobre novas experiências formativas.

Seguindo a ideia de apresentação das trajetórias percorridas, ao rememorarmos o primeiro semestre de 2012, nos remetemos a meses de intenso trabalho na UFES. Em um ambiente de constantes trocas, que envolvia coordenadores institucionais, ${ }^{3}$ coordenadores de área que estavam desenvolvendo subprojetos e professores da universidade que pretendiam elaborar subprojetos para áreas não contempladas até aquele momento, o processo de escrita do subprojeto também trouxe apreensão. Tanto nos discursos dos gestores da universidade quanto nas visões dos professores comprometidos com as licenciaturas, o Pibid representava uma importante conquista para a qualificação dos cursos de formação de professores.

Então, por mais que os diálogos e trocas com os colegas da universidade trouxessem estimulantes contribuições, sentimos o peso da responsabilidade em aprovar subprojetos que ampliariam os espaços de formação docente, além dos potenciais desdobramentos sobre as práticas curriculares acadêmicas, os projetos de extensão, as pesquisas etc.

Passada a fase da escrita, o colegiado do Pibid/UFES aguardou com grande expectativa o resultado dos subprojetos submetidos à avaliação da Coordenação de Aperfeiçoamento de Pessoal de Nível Superior (Capes) naquele ano. Ao recebermos a notícia da aprovação, entre junho e julho o trabalho ganhou outras dimensões com a procura por instituições públicas de ensino que atendessem os requisitos solicitados pela Capes, o lançamento de editais para a seleção de bolsistas que participariam das atividades na universidade e nos ambientes escolares, além das reuniões do colegiado de coordenadores do Pibid que 
visavam aproximar e entrosar os grupos de bolsistas que compunham todo o projeto institucional.

Após toda a preparação necessária que antecede os processos formativos do programa, no mês de agosto de 2012 o subprojeto iniciou suas atividades na UFES e em duas instituições de ensino da cidade de Vitória (ES), a Escola Estadual de Ensino Fundamental e Médio Irmã Maria Horta (IMH) e a Escola Municipal Rita de Cássia Oliveira (RCO). As professoras selecionadas da disciplina História, respectivamente Katia Valeska Azevedo e Ticiana Pivetta Costa, assumiram a função de supervisoras e trabalharam diretamente com 8 bolsistas ID em cada escola.

Com a remoção da professora Ticiana para outro cargo da Prefeitura Municipal de Vitória em junho de 2013, a escola RCO ficou sem um professor que pudesse atender os requisitos da Capes para a função de supervisor. Dessa forma, realizamos nova busca por uma unidade de ensino que atendesse tais requisitos, que nos levou até a Escola Municipal de Ensino Fundamental José Áureo Monjardim (JAM), também situada na capital do Espírito Santo, onde foi selecionada para a supervisão a professora Mônica Cardoso de Lima. Os bolsistas ID que atuavam na RCO foram transferidos para a escola JAM a partir de julho de 2013.

Durante o período focalizado, o subprojeto foi desenvolvido na perspectiva de colaboração entre todos os participantes, no sentido de valorizar-se o diálogo aberto, com vistas a potencializar as trocas de experiências, as discussões pedagógicas, o planejamento coletivo dos projetos de ensino e as leituras teóricas, dentre outras atividades. Se por um lado o decreto que dispõe sobre o Pibid ${ }^{4}$ procura definir as atribuições de cada bolsista de forma compartimentalizada, por outro, nossos princípios educacionais e experiências formativas nos instigaram a problematizar possíveis interpretações hierarquizantes.

Acreditando que o comprometimento de cada bolsista era fundamental para a efetivação da perspectiva de colaboração que estávamos propondo, tratamos de explicar previamente os objetivos gerais do programa e os objetivos específicos do subprojeto de História, relacionando-os às demandas curriculares das escolas e fomentando discussões acerca dos possíveis projetos de ensino a serem desenvolvidos. Em nosso entendimento, tais encaminhamentos viabilizariam, por exemplo: a) uma compreensão mais ampla do programa e do papel de cada bolsista para a consecução das atividades; b) a participação 
coletiva nas discussões curriculares; c) o esclarecimento de possíveis questionamentos no decorrer dos trabalhos; d) o compartilhamento das decisões; e) a distribuição consensual de tarefas na pesquisa de referências e/ou na elaboração de recursos didáticos; f) a execução conjunta dos projetos de ensino; e g) a autoavaliação dos bolsistas no decorrer do próprio processo formativo.

Assim, buscamos uma tessitura coletiva no âmbito do subprojeto, a qual foi estimulada, dentre outras referências, pelas contribuições da historiadora Maria Carolina Bovério Galzerani. Na Faculdade de Educação da Universidade Estadual de Campinas (Unicamp), Galzerani atuou na docência, extensão e pesquisa na área de ensino de História defendendo projetos de ensino construídos coletivamente, a produção de saberes históricos escolares, as funções sociais da escola pública e o valor de seus profissionais. ${ }^{5}$ Inspirados também por referenciais teórico-metodológicos ${ }^{6}$ próximos da linha adotada pela professora Galzerani, discutíamos as experiências curriculares e os textos elencados em reuniões realizadas nas escolas e nas dependências do Laboratório de Ensino de História (Lahis), localizado no Centro de Educação da UFES.

Com a realização de reuniões periódicas em meio ao desenvolvimento das atividades, a proposta de tessitura coletiva do subprojeto passou a ser gradativamente compreendida pelos bolsistas. Entretanto, posturas de estranhamento foram recorrentes diante de um programa de formação que não apresenta um modelo pronto, definido previamente, a ser "aplicado" nas escolas. Por isso, era plenamente compreensível os bolsistas ID perguntarem inúmeras vezes: "Como é que eu tenho que fazer?"; "Que parte eu tenho que fazer?"; "Que conteúdos devem ser aplicados na sala de aula?”.

As posturas de estranhamento também foram observadas diante da própria dinâmica das reuniões. Inicialmente, os bolsistas ID tinham receio de expressar suas opiniões frente ao professor da universidade ou frente às professoras supervisoras. Notava-se a preocupação dos estudantes de graduação em não discordar de seus professores, em não errar perante o grupo, em não expor ideias inconsistentes ou pouco elaboradas. Oriundos de culturas escolares pouco democráticas (para não utilizar a palavra tradicionais), e imersos em ambientes acadêmicos competitivos, que reforçam visões hierarquizadoras, a maior parte dos bolsistas ID estava habituada a encontrar propostas de ensino uniformizadoras, marcadas pela racionalidade técnica-instrumental. 
Dessa maneira, os bolsistas levaram algum tempo para perceber que o espaço de trabalho do subprojeto não valorizava tais concepções e práticas.

Consideramos que traços culturais hierarquizadores e individualistas, pautados ainda por concepções de racionalidade técnica-instrumental, concorreram para determinadas formas de resistência à proposta de tessitura coletiva do nosso subprojeto. Não são poucos os sujeitos que pensam que trabalhar sozinho é mais fácil. Segundo os adeptos dessa vertente, o cumprimento de tarefas individualizadas evita tensões, além de destacar as diferenças entre os que realizam e os que não realizam. No que tange aos espaços escolares, quem não reconhece a valorizada competição entre estudantes a partir das notas aferidas? Quem nunca passou por estudos estritamente disciplinares? Quem não sabe de casos de ausência de diálogo entre equipe gestora, professores e comunidade escolar? Esses e outros aspectos relacionados às culturas escolares perpassam determinadas experiências dos bolsistas que integraram o Pibid História da UFES.

Nesse sentido, superar práticas culturais prevalecentes na contemporaneidade se constituiu em um dos grandes desafios para o desenvolvimento de nossas atividades. Ao buscar a tessitura coletiva do subprojeto, acreditamos que no rol de nossas atribuições (na condição de professores responsáveis pelo processo formativo dos bolsistas ID), a articulação de distintas expectativas com relação ao programa deveria passar pela problematização das práticas de ensino historicamente consolidadas da disciplina, das perspectivas de formação nos cursos de Licenciatura e da compreensão do que significa produzir e difundir conhecimento histórico.

\section{Compartilhamento DE IDEIAS}

E PROCESSOS FORMATIVOS NA ESCOLA IMH

Sabemos que determinadas pesquisas da área de educação que abordam as relações entre professores universitários e professores da Educação Básica apresentam análises sobre posturas de desconfiança mútua, de distanciamento ou de dificuldades para o estabelecimento de diálogos profícuos. Diferentemente de situações embaraçosas que reconhecemos em muitas relações nos ambientes profissionais acima citados, no decorrer das atividades de nosso subprojeto conseguimos construir valiosas experiências, pautadas pela 
perspectiva de colaboração, trabalhando no intuito de consolidar as práticas de tessitura coletiva dos processos formativos.

Se nós, professores, construímos experiências significativas no decorrer das atividades, a participação do grupo de bolsistas ID concorreu muito para esse quadro. Na condição de responsáveis pelo desenvolvimento do subprojeto, tínhamos a constante preocupação de solicitar empenho e comprometimento dos bolsistas, mesmo que na maior parte do tempo tais solicitações não fossem necessárias. Nas reuniões periódicas, nos ambientes escolares, nos encontros cotidianos, enfim, em diferentes momentos e espaços, reafirmávamos a necessidade de nos comprometermos com os processos educativos dos estudantes das escolas públicas, de compartilharmos ideias, de explicitarmos sugestões para que todos compreendessem que somente a efetiva participação de cada um garantiria a tessitura coletiva dos projetos de ensino e demais atividades programadas.

No caso da escola IMH, situada no bairro da Praia do Canto em Vitória, trabalhamos com estudantes que cursavam o Ensino Médio (EM) no período vespertino. Antes de discorrermos sobre as atividades do Pibid, queremos ressaltar uma questão. A localização dessa escola pública é privilegiada para os padrões do mercado imobiliário local. A Praia do Canto é considerada uma das áreas nobres da cidade, sendo bem atendida nos setores de serviços, transportes e lazer. Entretanto, o corpo discente dessa escola é composto majoritariamente por sujeitos que residem em áreas carentes da cidade ou outros municípios da região metropolitana. A escola pública, encravada em um bairro onde encontramos edifícios e residências de alto padrão, acaba recebendo estudantes que não representam seus típicos moradores ou frequentadores. Seja pelo constante barulho gerado na escola, seja pela circulação indesejada de muitas pessoas nas proximidades de suas residências ou pontos comerciais, ruidosas reclamações contra a $\mathrm{IMH}$ são proferidas cotidianamente. Contradições da cultura contemporânea: os mesmos que defendem publicamente a educação escolar como meio de superação dos mais variados problemas sociais são aqueles que acabam se indispondo com a localização das instituições de ensino, quando estas podem atrapalhar seus negócios ou desvalorizar seu patrimônio. Entretanto, se algumas vozes explicitam suas críticas e rejeições, outras defendem a importância da instituição pública instalada em uma edificação que tem sua fachada tombada pelo patrimônio municipal. 
É nesse cenário escolar que nosso subprojeto contou na primeira fase ${ }^{7}$ com a participação de 8 bolsistas ID, trabalhando sob a supervisão da professora Katia Valeska Azevedo. A partir da segunda fase, iniciada em março de 2014, o número de bolsistas foi redefinido para 6. Nas duas fases, a inserção dos licenciandos bolsistas no sistema público de ensino procurou alcançar os objetivos do subprojeto, dentre os quais destacamos a busca em apreender sobre os sujeitos pertencentes à comunidade escolar. Desde os primeiros momentos, os bolsistas foram estimulados a levantar e analisar o perfil sociocultural dos estudantes, professores, gestores e funcionários, visando uma melhor compreensão de suas demandas.

A tarefa de observar e analisar as dinâmicas relações que constituem um espaço escolar provocou certa resistência. Habituados a elaborarem um diagnóstico inicial e definitivo para o desenvolvimento de análises conjunturais, determinados bolsistas expressavam sua insatisfação com o "tempo perdido". Visando demover as posturas de resistência, ressaltávamos que tal tarefa deveria ser realizada na perspectiva processual, pois somente dessa forma as abrangentes especificidades da cultura escolar ${ }^{8}$ focalizada seriam percebidas, ora por meio de suas permanências, ora por meio das mais sutis mudanças.

O “tempo não perdido" de tais observações e análises serviu para os bolsistas se aproximarem efetivamente dos sujeitos que produzem a cultura escolar. Essa aproximação propiciou o estabelecimento de diálogos com os integrantes da comunidade, potencializando o reconhecimento das expectativas dos estudantes do EM, a identificação de regras, normas e ações que envolvem o cotidiano da IMH, a leitura mais ampla dos problemas de aprendizagem na disciplina História e a constatação das condições de trabalho dos profissionais da Educação Básica. Assim, os bolsistas puderam perceber que as dificuldades que os docentes em geral têm ao lidar com as dinâmicas relações - as quais redefinem constantemente a cultura escolar - são mais complexas do que determinados "especialistas" insistem em propagar, com fórmulas simplistas, mecanicistas e descontextualizadas.

Considerando as demandas curriculares propostas pela Secretaria de Estado da Educação (Sedu) do Espírito Santo e as expectativas enunciadas pela comunidade escolar, os integrantes do Pibid História discutiram a necessidade da incorporação de novos conteúdos aos tradicionalmente ministrados no EM. Com a intenção de desenvolvermos estratégias de trabalho que valorizassem o magistério público, investigando desde as carências existentes no contexto 
escolar até os avanços do ensino da disciplina História, refletimos acerca do uso de linguagens alternativas nas aulas (músicas, artes plásticas, gêneros literários, poesias, documentários, memórias orais, charges, quadrinhos, redes sociais etc.), principalmente as linguagens que potencializassem abordagens de temas transversais e interdisciplinares, ampliando os diálogos entre os denominados saberes escolares e os conhecimentos acadêmicos. ${ }^{9}$

Definimos que os estudos e/ou as propostas de metodologias potencializadoras para as aulas de História deveriam levar em conta as práticas de ensino interdisciplinares, adequando-as ao contexto escolar focalizado a partir das sensibilidades dos discentes e docentes implicados. Para a realização de tais objetivos, a cada projeto de ensino que pretendíamos desenvolver, foram realizadas reuniões preliminares (planejamento) e periódicas (avaliação processual) com a participação dos bolsistas e dos professores de outras disciplinas escolares envolvidas. As reuniões constituíram-se em importantes espaços de atuação dos bolsistas ID, pois, ao acompanharem o diálogo entre professores de distintas disciplinas escolares, estes puderam discutir e participar da definição dos objetivos, justificativas, metodologias e possíveis encaminhamentos dos projetos de ensino. As reuniões também foram importantes para os bolsistas compreenderem as demandas de diferentes disciplinas escolares, rompendo com a ideia da centralidade da área da História, tão propagada na formação com viés bacharelesco. Dessa forma, as discussões relativas aos projetos de ensino possibilitaram olhares sobre os limites e as potencialidades dos estudos interdisciplinares na Educação Básica, além de concorrerem para a consolidação de nossa proposta de tessitura coletiva do subprojeto.

Dentre os inúmeros projetos de ensino planejados e executados no período, destacamos os que tiveram significativos desdobramentos na formação dos bolsistas ID. Isso aconteceu, por exemplo, no primeiro trimestre de 2013 com o projeto "História em Jogo", destinado às turmas de $1^{\circ}$ ano do EM. Definimos como objetivo geral do projeto abordar os processos históricos da Antiguidade por meio da elaboração de materiais lúdicos. Propondo a confecção de jogos aos estudantes, também pretendíamos estimular o desenvolvimento de noções espaciais, raciocínio lógico, organização de informações, construção de hipóteses e resolução de problemas. Ultrapassando os tradicionais limites da disciplina, nos aproximamos de conhecimentos tratados historicamente por outras áreas. Do ponto de vista da instituição escolar, contamos com a participação da professora de Artes, que auxiliou os estudantes na 
perspectiva das habilidades artísticas e nos processos criativos. Acompanhando desde o planejamento até a avaliação dos trabalhos elaborados pelos estudantes do $1^{\circ}$ ano, a professora de Artes possibilitou que os bolsistas ID observassem as demandas de outra disciplina enquanto trabalhavam os conteúdos históricos. O que pode parecer um projeto sem grandes repercussões ou originalidade, principalmente para os bolsistas em formação, acabou despertando maior atenção aos potenciais diálogos interdisciplinares ${ }^{10}$ no estudo da história.

Observamos outra disposição dos bolsistas ID, em valorizar procedimentos e conceitos de outros campos do conhecimento, no acompanhamento das equipes de estudantes que se inscreveram na $5^{\text {a }}$ Olimpíada Nacional em História do Brasil (ONHB). Projeto de extensão elaborado pelo Departamento de História da Universidade Estadual de Campinas (Unicamp), a ONHB instiga os inscritos a estudarem a história brasileira por meio de mapas, documentos, imagens e textos. As equipes participantes devem responder questões de múltipla escolha e realizar tarefas que colocam em ação procedimentos tradicionalmente utilizados nas disciplinas Geografia, Português, Matemática e Artes, dentre outras, além da própria disciplina História.

Visando tratar a ONHB como uma oportunidade de debatermos a produção de conhecimento, propusemos aos bolsistas a análise das provas das edições anteriores, refletindo sobre seu formato inovador e suas potencialidades pedagógicas. As atividades de preparação e acompanhamento da Olimpíada transcorreram entre o $2^{\circ}$ e o $3^{\circ}$ trimestres de 2013, paralelamente ao desenvolvimento de outros projetos.

Acreditamos que o viés interdisciplinar das tarefas e questões da ONHB deslocou ainda mais os olhares dos bolsistas ID, pois eles esperavam um certame nos moldes tradicionais, baseado no acúmulo de informações sistematizadas e restritas ao campo da História. Assim, a Olimpíada contribuiu para o desenvolvimento de nosso subprojeto, incentivando o estudo coletivo dos temas abordados, desconstruindo a concepção acumulativa do conhecimento, tratando-o como uma produção sociocultural datada. As equipes da IMH não conseguiram alcançar a fase final da ONHB, mas os estudantes da escola procuraram o apoio dos bolsistas para participarem da 6a edição em 2014.

No $1^{\circ}$ semestre de 2014, buscando ampliar as dimensões curriculares e pedagógicas da escola, as atividades do subprojeto estiveram voltadas para que os estudantes do $3^{\circ}$ ano do EM conhecessem e refletissem sobre 
acontecimentos recentes da história nacional. Articulando com os professores de Geografia e Língua Portuguesa um projeto interdisciplinar, propusemos um estudo que abarcasse os 50 anos do golpe de 1964. Dessa forma surgiu o projeto “Ditadura Militar no Brasil (1964-1985)", que acabou focalizando, sobretudo, questões culturais do referido período histórico. Os bolsistas participaram ativamente de todo o projeto, propondo temas, discutindo sua viabilidade, organizando e auxiliando os grupos de estudantes, dialogando com os professores das outras disciplinas e preparando aulas específicas sobre os temas selecionados, dentre outras atribuições realizadas.

Ao entrarmos em consenso, apresentamos para as turmas do $3^{\circ}$ ano os temas que seriam trabalhados no projeto interdisciplinar: Literatura, Música, Teatro, Cinema, Fotografia, Propaganda e Mídia. Como produtos finais do projeto, os grupos de estudantes deveriam produzir um trabalho escrito seguindo as normas da Associação Brasileira de Normas Técnicas (ABNT) e preparar uma apresentação, que ocorreu no Auditório do Centro Tecnológico da UFES.

O projeto sofreu uma interrupção com greve dos professores estaduais, mas ao final do semestre as produções dos estudantes foram muito significativas. As atividades desenvolvidas possibilitaram que os estudantes da IMH produzissem conhecimento a partir dos temas focalizados. Por meio do projeto interdisciplinar, os bolsistas ID puderam analisar os procedimentos de pesquisa de diferentes áreas, refletindo sobre o currículo e sua historicidade. Os embates epistemológicos e pedagógicos em torno das concepções de conhecimento ganharam novas dimensões após as experiências compartilhadas pelos bolsistas. Dessa forma, entendemos que os processos formativos na escola IMH foram marcados por momentos de satisfação com os objetivos alcançados, mas também trouxeram indagações importantes com relação ao papel social dos professores na contemporaneidade.

\section{AS EXPERIÊNCIAS CURRICULARES E FORMATIVAS NA ESCOLA JAM}

Em decorrência da necessária substituição da escola RCO, os primeiros contatos dos bolsistas ID com os estudantes do JAM ocorreram no mês de agosto de 2013, logo após o período de férias. Ao contrário da instituição anterior, localizada no bairro de Resistência, região periférica da capital e pouco assistida pelos poderes públicos, o JAM está situado em Fradinhos, área 
valorizada da cidade, caracterizada por ser um bairro de classe média alta. De forma semelhante à escola IMH, a maioria dos seus estudantes é proveniente de áreas próximas, como os bairros de Jucutuquara e Tabuazeiro, além dos morros do Cruzamento e do Romão.

Com a divisão equitativa do número de bolsistas ID $^{11}$ entre as escolas, os do JAM atuaram com estudantes que cursavam os anos iniciais e finais do Ensino Fundamental, sob a supervisão da professora Mônica Cardoso de Lima. No período recortado, a escola teve aproximadamente 450 matrículas/ano, enquanto nosso subprojeto envolvia uma média de 130 estudantes distribuídos em turmas correspondentes ao $4^{\circ}, 6^{\circ}, 7^{\circ}, 8^{\circ}$ e $9^{\circ}$ anos.

Diferentemente do cenário existente em outras instituições de ensino, nas quais os docentes não conseguem colocar em ação o seu Projeto Político Pedagógico (PPP) por diversos motivos, a professora de História do JAM procura fundamentar suas práticas pedagógicas no referido documento. O PPP da escola organiza o ensino em ciclos de aprendizagem, no caso, em quatro ciclos para o Ensino Fundamental.

Uma das características desses ciclos configura-se numa perspectiva distinta das práticas de aprovação/retenção de estudantes. Se antes da adoção dos ciclos de aprendizagem as aprovações ou retenções ocorriam ao final de cada ano, depois da adoção tais práticas passaram a ocorrer bienalmente, isto é, ao final de cada ciclo, proporcionando ao estudante mais tempo para alcançar os objetivos propostos.

Segundo a proposta do PPP da instituição, a avaliação deve ser realizada por objetivos, os quais foram selecionados a partir dos Parâmetros Curriculares Nacionais (PCN) e do Documento Norteador da disciplina, elaborado por professores da rede municipal de ensino da cidade de Vitória no ano de 2003. Atualmente, a rede está promovendo um novo processo de Formação Continuada com o intuito de fomentar alterações no currículo das unidades municipais de ensino.

O Documento Norteador das ações relacionadas ao processo de ensino e aprendizagem estimula os professores responsáveis pelas disciplinas escolares a atuarem em projetos interdisciplinares, de forma dialógica, buscando compreender o objeto de conhecimento como um processo, tal como descrito nesta passagem do PPP: 
Os procedimentos pedagógicos e os métodos escolhidos para a nossa prática escolar estão fundamentados na noção de que o conhecimento é um processo, uma construção que tem na prática social concreta da humanidade seu ponto de partida e de chegada. $\mathrm{O}$ ato de conhecer pressupõe a interdependência e a complementação entre o sujeito e o objeto, considerando aqui o caráter dialético das interações entre estes dois elementos na construção do conhecimento. O conhecimento é, portanto, um processo que tem como características gerais ser prático, social e histórico. ${ }^{12}$

Posicionar-se em relação às visões que os profissionais da educação apresentam sobre o ato de conhecer é fundamental para a formação dos bolsistas ID. A problematização das visões epistemológicas e/ou pedagógicas que defendem a concepção do conhecimento dado a priori permite o reconhecimento dos atores históricos, de seus papéis sociais e suas inserções nos processos dialógicos de produção de um determinado conhecimento.

Considerando as culturas escolares e seus desdobramentos históricos, é um desafio enorme trabalhar com a noção processual de produção do conhecimento nos espaços formais de educação. Enquanto as atividades do subprojeto eram desenvolvidas no JAM, observamos posturas de estudantes e licenciandos da UFES que oscilavam entre buscar elementos para a produção do conhecimento e apenas tratá-lo como algo a ser adquirido ou transmitido. Por mais leituras e discussões realizadas no sentido de ressaltar as perspectivas práticas e socioculturais relativas ao processo de produção do conhecimento, parte significativa dos sujeitos citados apresentou a tendência de reafirmar visões epistemológicas e pedagógicas conservadoras. Para explicitarmos melhor essa ideia, relataremos na sequência experiências curriculares que tiveram a interação com os bolsistas ID.

No ano de 2013, a escola tinha duas turmas, uma do $3^{\circ}$ e outra do $4^{\circ}$ Ciclo (correspondentes aos $7^{\circ}$ e $8^{\circ}$ ano), que apresentavam grande dificuldade tanto na compreensão das práticas de ensino do JAM, como na construção de sua identidade estudantil. A presença de estudantes do curso de História da UFES a partir de agosto colaborou enormemente para um "empoderamento" da disciplina, ao mesmo tempo em que destacou a necessidade de os estudantes das referidas turmas assumirem novos "lugares" no espaço escolar, ou seja, de passarem a ser protagonistas de seus aprendizados. 
A atuação dos bolsistas ID nas aulas, acompanhando as discussões e colaborando com os grupos de estudo, foi significativa para a construção desse protagonismo. No caso da turma do $4^{\circ}$ Ciclo, descrevemos com mais detalhes essa atuação. Os estudantes da turma tinham que realizar uma pesquisa visando a participação em um debate no qual discutiriam as ideologias do século XIX: o liberalismo, o anarquismo, o socialismo cristão, o socialismo científico e o socialismo utópico. Cada grupo da classe reuniu-se no decorrer de quatro semanas com um bolsista previamente selecionado, o qual apoiou o desenvolvimento das pesquisas, a seleção de textos, as leituras e, finalmente, a compreensão e discussão dos princípios de uma ideologia a ser defendida e de outra a ser criticada.

Após toda a fase de execução das atividades, os grupos estavam preparados para o debate, com argumentações elaboradas de defesa de determinado princípio ou de crítica a outro princípio ideológico. Apesar de ter se constituído em um trabalho complexo, que gerou reclamações por parte dos estudantes, um fato chamou a atenção. No dia em que o debate estava marcado, a professora sofreu um acidente de trânsito, sendo obrigada a ausentar-se da escola por um tempo. Para nossa surpresa, os estudantes que tanto resistiram às atividades ao longo do projeto de ensino reivindicaram com insistência junto aos bolsistas a realização do debate em uma data posterior, mesmo com o afastamento da professora. A insistente reivindicação dos estudantes em prol da realização do debate pode ser interpretada como uma conquista no processo de aprendizado, no qual eles assumem o protagonismo de forma autônoma.

Em outra experiência que se refere às concepções de conhecimento que circulam na escola, tivemos um conjunto de aulas ministradas pelos bolsistas ID no ano de 2014, na turma do $4^{\circ}$ ciclo (correspondente ao $9^{\circ}$ ano). Essa turma em 2013 era uma daquelas que demonstrava grau elevado de resistência às práticas de ensino do JAM. Determinados estudantes não compreendiam que no fundamento pedagógico de ensino da escola, a ênfase aos projetos de ensino não permitia abordagens meramente "conteudistas". As aulas pautadas nas práticas dialógicas e no estímulo à produção de conhecimento, a partir de questões concretas da realidade local, desencadeavam a resistência dos estudantes que preferiam os conteúdos formais e as avaliações tradicionais.

Visando superar a apatia e desmotivação da turma diante dos estudos históricos, acertamos com os bolsistas ID que eles assumiriam algumas aulas. 
Planejadas coletivamente, as aulas buscavam garantir a apresentação de informações relacionadas aos temas específicos do conteúdo programático. Optando preferencialmente por apresentações pautadas em recursos multimídia, os bolsistas pretendiam despertar a atenção da turma, ao mesmo tempo em que sistematizavam as principais informações a serem trabalhadas. A partir desse encaminhamento, cabia aos estudantes da escola realizar os registros e responder a instrumentos avaliativos elaborados, na maioria das vezes, na forma de questões objetivas.

Essa metodologia viabilizou o cumprimento dos conteúdos e objetivos curriculares do ciclo no reduzido tempo que restava. No entanto, a metodologia não garantiu uma nítida percepção de qual aprendizado ou de que apropriação de conceitos pôde ser realizada por parte dos estudantes.

Um aspecto que consideramos relevante nessa experiência curricular é que tanto os estudantes da escola quanto os bolsistas da universidade avaliaram positivamente as aulas e seus resultados. Elogiando as apresentações dos bolsistas, os estudantes da turma passaram a ter um comportamento diferente na sala de aula, com menos conversas paralelas e mais atenção dispensada ao "bolsista-professor", além de respeitarem os prazos de entrega das tarefas propostas. Podemos inferir que na visão da pedagogia tradicional, os estudantes tiveram o comportamento desejado em sala de aula.

Sobre essa experiência, os bolsistas ID fizeram as seguintes considerações:

A interferência do Pibid no 4c3 (corresponde ao $9^{\circ}$ ano) no ano de 2014 resultou em uma mudança de postura da turma em relação à disciplina de História. A princípio, a turma demonstrava certa apatia em relação à disciplina, o que gerava um incômodo tanto para a professora quanto para os pibidianos. Visando promover uma mudança de comportamento da turma, os pibidianos começaram a ministrar aulas, trazendo uma nova abordagem. As aulas dos pibidianos geralmente eram ministradas fora da sala de aula. O conteúdo era trabalhado utilizando recursos de multimídia que alteraram a rotina escolar anterior. Esta mudança surtiu efeito no comportamento de alguns alunos. Estudantes que anteriormente não se interessavam pela matéria passaram a se envolver com a aula, chegando até a superar as expectativas. ${ }^{13}$

É importante afirmar que na rotina da escola sempre se utilizam recursos multimídia, geralmente em aulas que acontecem na sala de informática ou na 
sala de vídeo. Logo, a "nova abordagem" trazida pelos bolsistas, visando alterações de comportamento da turma, está relacionada ao método não observado nas práticas de ensino da professora supervisora.

As aulas expositivas atenderam os anseios de parte dos estudantes oriundos de estabelecimentos particulares, que faziam comparações entre as práticas de ensino do JAM e as de outras escolas. Nessa experiência, tanto os estudantes da escola quanto os da universidade pareciam compartilhar e valorizar a visão de conhecimento a ser transmitido. Dessa forma, enquanto o professor apresenta as informações essenciais para a compreensão do conhecimento, basta aos estudantes adquiri-los.

Mas essa avaliação positiva da experiência curricular não estaria relacionada, por parte dos bolsistas ID, à suposta eficiência do método de ensino, capaz de "acalmar" os estudantes, que também se mostraram mais interessados nas aulas? Não ser rejeitado pelos estudantes é um sinal de eficiência pedagógica? Por parte dos estudantes do JAM, avaliação positiva não estaria relacionada com a percepção de que o processo de aprendizagem foi simplificado, com estudos baseados em informações prontas e tarefas mecânicas, sem a complexidade da produção do conhecimento por meio de pesquisas, reflexões, argumentações etc.?

A alternativa para melhorar a relação da turma nas aulas de História, tendo em vista a atitude de desinteresse de parte dos estudantes, ocorreu em comum acordo entre os integrantes do subprojeto. Sem dúvida, é inegável a qualidade das apresentações, dos slides elaborados, dos documentos visuais selecionados e das aulas preparadas pelos bolsistas. Entretanto, consideramos importante destacar a necessidade de discutirmos o que é o conhecimento, tanto nos espaços escolares como nos espaços acadêmicos.

No JAM há uma divisão entre os profissionais da educação: uns defendem o PPP e suas premissas teóricas e pedagógicas, outros querem retornar à seriação, à avaliação tradicional, ao sistema de notas, ou seja, querem pôr fim ao projeto de ensino iniciado nos anos 1990 que privilegia o diálogo, a mediação entre o universo cultural dos estudantes e a necessidade de sistematização do saber escolar.

Há, portanto, uma postura teórico-metodológica em questão, e outro indício disto é a resistência por parte de estudantes da escola e de suas famílias 
para o entendimento do que a escola tem, ou se esforça em ter, em relação ao ato do conhecimento.

\section{PARA CONTINUARMOS NOSSOS DiÁlOGOS}

Procuramos relatar neste texto experiências significativas, tanto para os bolsistas ID quanto para nós, professores responsáveis pelos processos formativos do subprojeto. Porém, não esquecemos que os processos não devem ser vistos em fragmentos isolados, valorizando os momentos exitosos e apagando os possíveis problemas encontrados no decorrer do trabalho. Ao destacarmos os projetos de ensino que tiveram boa repercussão nas comunidades escolares e entre os bolsistas, contamos com as dificuldades de outros para superarmos resistências, críticas e falta de apoio aos projetos em destaque.

Em nossa trajetória, os bolsistas ID participaram ativamente das atividades propostas nas escolas, ademais de se ambientarem aos seus respectivos espaços. Para a maioria do grupo, o subprojeto viabilizou a primeira experiência ao lado de professores da Educação Básica. Norteando as atividades, a proposta de tessitura coletiva manteve-se presente visando a potencialização das atuações docentes e discentes nas escolas públicas.

Partindo de nossas experiências, consideramos que a presença dos bolsistas ID nas escolas indiscutivelmente qualifica o ensino e a aprendizagem da disciplina, especificamente naquilo que diz respeito ao conhecimento histórico: a compreensão dos processos, a percepção da existência de agentes históricos, a identificação de conflitos entre grupos sociais, a pluralidade de interesses políticos. O campo do ensino da História pressupõe atividades que exigem do estudante a curiosidade, um desprendimento de sua subjetividade, certo grau de abstração, o aprendizado de conceitos específicos, o interesse pela leitura e a busca de comparações ou conexões de múltiplas temporalidades e espacialidades. Ou seja, quem afirma que História é "fácil" não compreende a complexidade, as ambiguidades e as ambivalências de um objeto de estudo da área.

Sem a intenção de simplificar o processo de ensino e aprendizagem, elaboramos coletivamente os projetos refletindo sobre as possibilidades de produção de conhecimento. As posturas dos bolsistas em sala de aula geraram um clima de debate, fortalecendo a disciplina naquilo que ela pode proporcionar aos sujeitos na fase em que eles se encontram, isto é, a consciência de si mesmo 
e de seu entorno, assim como o reconhecimento de uma memória étnica, patrimonial e histórica como forma de contribuir na construção de suas identidades.

Sabemos que a inserção dos bolsistas ID no cotidiano de uma escola é um desafio em qualquer momento. Além de promover mais um trabalho de intermediação entre os sujeitos da comunidade escolar, existe a questão da restrição dos tempos. As atividades na escola são variadas, e as que pressupõem a interdisciplinaridade exigem tempos de planejamento individual e coletivo que geralmente extrapolam os limites da carga horária semanal dos professores.

O trabalho de supervisão do Pibid estabelece uma mobilização incomum por parte do profissional da educação, pois há uma ampliação das funções e das relações nos espaços escolares que demandam esforços de reflexão e planejamento diferenciados. Sem dúvida, os bolsistas colaboram intensamente no cotidiano do supervisor, seja participando das tarefas de planejamento, da seleção de documentos, da elaboração de apresentações multimídia, seja na contribuição do acompanhamento individual ou de grupos de estudantes, fazendo a intervenção nos modos de ensinar e aprender. Mesmo assim, essas e outras ações ampliam a necessidade de o supervisor refletir acerca das práticas escolares, dos métodos desenvolvidos em sala de aula, dos processos avaliativos e de sua própria formação continuada.

Nesse ponto, o Pibid atinge um de seus objetivos primordiais, que é elevar a qualidade da formação dos professores da Educação Básica, pois nada poderá transformar mais esse nível de ensino, no sentido de qualificá-lo, do que possibilitar aos seus profissionais mais espaços de reflexão, diálogo e pesquisa.

Existe um descompasso entre número de horas-aula e o tempo de planejamento na jornada de trabalho de um profissional da Educação Básica. Como desejar uma qualificação das práticas escolares sem que seus profissionais tenham tempo individual ou coletivo de refletir sobre elas? Se partirmos do entendimento de que o processo de ensino e aprendizagem é coletivo, logo o profissional da educação deve se colocar diante do desafio de pensar coletivamente suas demandas, dificuldades ou necessidades. Neste ponto há mais um aspecto primordial para a percepção dos bolsistas ID: eles devem preparar-se para pensar não somente no campo de sua disciplina. O bolsista deve pensar suas ações no sentido de colaborar para que os estudantes da Educação Básica 
reúnam condições de produzir conhecimento, ou seja, que os processos educativos nesse nível de ensino valorizem a busca do pensamento autônomo.

Consideramos que é preciso defender a importância do programa de iniciação à docência quando, em seus desdobramentos práticos na escola, acaba por ressaltar uma evidência: a Educação Básica necessita de espaços de formação continuada, fomentados pelos órgãos gestores e pelo próprio profissional. Mas, além disso, é na unidade de ensino que os professores devem ter seus espaços de formação, com tempos de planejamento individual e coletivo, que permitam avaliar suas práticas pedagógicas e seus métodos de ensino.

Em outro aspecto, seria importante refletirmos sobre as concepções e formas de produção do conhecimento. Diante de nossas experiências, surgem algumas indagações: como desenvolver projetos de ensino interdisciplinares sem críticas ou resistências em comunidades escolares que valorizam conhecimentos compartimentalizados em disciplinas? Como formar professores comprometidos com a Educação Básica em cursos de licenciatura marcados pelo viés bacharelesco? O Pibid efetivamente tem condições de impactar nas discussões curriculares dos cursos de formação de professores? Infelizmente estamos longe de responder a essas questões. Mesmo assim, elas nos mobilizam para continuarmos refletindo e dialogando sobre os desafios que envolvem os processos educativos e formativos.

\section{REFERÊNCIAS}

BENJAMIN, Walter. Magia e técnica, arte e política: ensaios sobre literatura e história da cultura. Trad. Sérgio Paulo Rouanet. 7.ed. São Paulo: Brasiliense, 1994. (Obras escolhidas, v.1)

BERRIO, Julio Ruiz (Ed.) La cultura escolar de Europa: tendencias históricas emergentes. Madrid: Ed. Biblioteca Nueva, 2000. (Colección Memoria y critica de la Educación)

FARIA FILHO, Luciano Mendes et al. A cultura escolar como categoria de análise e como campo de investigação na história da educação. Educação e Pesquisa, São Paulo, v.30, n.1, p.139-159, 2004.

FAZENDA, Ivani Catarina Arantes. Integração e interdisciplinaridade no ensino brasileiro: efetividade ou ideologia. São Paulo: Loyola, 1979.

FREIRE, Paulo. Pedagogia do oprimido. Rio de Janeiro: Paz e Terra, 1987.

GALZERANI, Maria Carolina Bovério. Memória, História e Tempo: perspectivas te- 
órico-metodológicas para a pesquisa em Ensino de História. Cadernos do CEOM, Chapecó, SC: Argos, v.21, n.28, p.15-31, 2008.

GALZERANI, Maria Carolina Bovério. Memória, história e (re)invenção educacional: uma tessitura coletiva na escola pública. In: MENEZES, Maria Cristina (Org.) Educação, memória e história: possibilidades, leituras. Campinas, SP: Mercado das Letras, 2004. p.287-330.

Produção de saberes históricos escolares: o lugar das memórias. In: FERREIRA, Antonio Celso; BEZERRA, Holien Gonçalves; LUCA, Tânia Regina de (Org.) O historiador e seu tempo: encontros com a história. São Paulo: Ed. Unesp, 2008. p.223-235.

Práticas de ensino em projeto de educação patrimonial: a produção de saberes educacionais. Pro-Posições, Campinas, SP, v.24, n.1 (70), p.93-107, jan.-abr. 2013.

GAY, Peter. A experiência burguesa da Rainha Vitória a Freud: a educação dos sentidos. Trad. Per Salter. São Paulo: Companhia das Letras, 1988.

JULIA, Dominique. A cultura escolar como objeto histórico. Revista Brasileira de História da Educação, Campinas, SP: Ed. Autores Associados, n.1, p.9-43, jan.-jun. 2001.

LARROSA BONDÍA, Jorge. Notas sobre a experiência e o saber de experiência. Revista Brasileira de Educação, Rio de Janeiro, n.19, jan.-abr. 2002.

THOMPSON, Edward Palmer. A miséria da teoria ou um planetário de erros: uma crítica ao pensamento de Althusser. Trad. Waltensir Dutra. Rio de Janeiro: Zahar, 1981.

\section{NOTAS}

${ }^{1}$ O primeiro subprojeto da área de Licenciatura em História do Pibid/UFES foi aprovado pela Capes em meados de 2012, na seleção orientada pelo Edital Capes no 11/2012.

${ }^{2} \mathrm{O}$ segundo subprojeto da área de Licenciatura em História do Pibid/UFES foi aprovado pela Capes no final de 2013, na seleção orientada pelo Edital Capes nº 61/2013.

${ }^{3}$ Participando de diferentes editais da Capes relativos ao Pibid, a UFES desenvolveu, como outras IES, mais de um projeto institucional até o início de 2014.

${ }^{4}$ Decreto no 7.219, de 24 jun. 2010, que dispõe sobre o Programa Institucional de Bolsa de Iniciação à Docência - Pibid, e dá outras providências. Disponível em: www2.camara.leg. br/atividade-legislativa/legislacao; Acesso em: 23 mar. 2015.

${ }^{5}$ Pesquisando na área do ensino de História junto ao Programa de Pós-Graduação em 
Educação da Unicamp, Galzerani abordou temas como memória, patrimônio e educação das sensibilidades. Cf. os textos trabalhados no Pibid/UFES nas referências.

${ }^{6}$ Dentre os referenciais abordados, destacamos as contribuições de BENJAMIN (1994), GAY (1988), LARROSA BONDÍA (2002) e THOMPSON (1981).

${ }^{7}$ Como apontamos anteriormente, período entre agosto de 2012 e fevereiro de 2014.

${ }^{8} \mathrm{O}$ conceito de cultura escolar foi discutido no âmbito de nosso subprojeto a partir das experiências curriculares vivenciadas nas escolas públicas e das leituras de textos. Cf. os textos listados nas referências.

${ }^{9}$ A maior parte das discussões teóricas desenvolvidas no decorrer do subprojeto abordou as relações entre os denominados saberes educacionais e conhecimentos científicos. Diante da importância dessas relações para o processo de ensino aprendizagem, estimulamos os bolsistas a pesquisarem e debaterem tais conceitos e suas implicações no âmbito da formação docente.

${ }^{10}$ Segundo Paulo Freire (1987), por meio do processo metodológico da interdisciplinaridade, o sujeito pode construir o conhecimento a partir de suas relações com o contexto, a realidade e a cultura. Dessa forma, procura-se a manifestação da interdisciplinaridade em dois movimentos dialéticos: a problematização de determinada situação, pela qual se amplia a compreensão da realidade, e a sistematização dos conhecimentos de forma integrada. Na visão de Ivani Fazenda (1979), a interdisciplinaridade requer a transformação das perspectivas pedagógicas, com um processo formativo de professores adequado, e novas formas de ensinar, capazes de superar os métodos de transmissão de saberes disciplinares fundados no modelo hierárquico linear, oportunizando relações pedagógicas dialógicas.

${ }^{11} \mathrm{O}$ número de bolsistas ID que trabalharam no JAM, e a sua variação, segue o que explicitamos anteriormente no caso da escola IMH: 8 (oito) na primeira fase e 6 (seis) a partir da segunda fase, iniciada em março de 2014.

${ }^{12}$ Projeto Político Pedagógico da EMEF José Áureo Monjardim, p.28. Trabalho não publicado.

${ }^{13}$ Depoimento escrito por bolsistas ID em fevereiro de 2015.

Artigo recebido em 22 de abril de 2015. Aprovado em 15 de maio de 2015. 